\title{
Bacteriological Profile of Heart Valves Resected from Infective Endocarditis Patients
}

\author{
Manandhar S, ${ }^{1}$ Basnyat S, ${ }^{1}$ Sharma J, ${ }^{2}$ Pokhrel BM, ${ }^{3}$ Koirala B ${ }^{2}$ \\ ${ }^{1}$ Central Department of Microbiology, Tribhuvan University, ${ }^{2}$ Department of Cardiac Surgery, Shahid Gangalal National \\ Heart Centre, ${ }^{3}$ Department of Clinical Microbiology, Institute of Medicine, Tribhuvan University Teaching Hospital
}

\section{ABSTRACT}

Background: Early prosthetic valve endocarditis is a serious life threatening infection of newly implanted prosthetic heart valve. A positive post-surgery heart valve culture is a significant risk factor for development of early prosthetic valve endocarditis.

Methods: A prospective bacteriological investigation was done in intraoperatively suspected and preoperatively diagnosed infective endocarditis patients undergoing heart valve replacement surgery. The valve samples were cultured after prior homogenization by sterile scalpel method. The bacterial isolates were identified by standard microbiological techniques and their antibiotic susceptibility profile was determined in vitro by Kirby Bauer disc diffusion method.

Results: Of 31 heart valve samples cultured, 3 (9.67\%) were culture positive which constituted 2 (13.33\%) from preoperatively diagnosed infective endocarditis patients from which Staphylococcus aureus and Enterococcus faecalis were isolated and 1 (6.25\%) from intraoperatively suspected infective endocarditis patient from which Staphylococcus aureus was isolated. All three isolates were sensitive to antibiotics Vancomycin and Ciprofloxacin and resistant to Penicillin and Amoxycillin. The isolates obtained from preoperatively diagnosed patients were more resistant to antibiotics tested than that from suspected patients.

Conclusions: The bacteriological examination of heart valves resected from preoperatively diagnosed and intraoperatively suspected infective endocarditis patients revealed higher degree of culture positivity. Hence routine microbiological examination of all heart valves from diagnosed and suspected IE patients is required to rule out active endocardial infection to reduce the chance of early prosthetic valve endocarditis.

Key words: bacteriology, heart valves, infective endocarditis

\section{INTRODUCTION}

Infective endocarditis (IE) is a serious infection of heart valvesandendocardium caused mainlybybacteria. Though
IE is relatively uncommon compared with other heart diseases, it is associated with significant morbidity and mortality. ${ }^{1}$ A positive blood culture is a major diagnostic criterion for IE. ${ }^{2}$ However it is persistently negative in

Correspondence: Ms. Sulochana Manandhar, Central Department of Microbiology, Tribhuvan University, Kirtipur, Nepal. Phone: 4240184, Email: perfectionsulo@ gmail.com 
$5-10 \%$ of patients who satisfy diagnostic criteria for IE often delaying diagnosis and management with profound impact on clinical outcome. ${ }^{3} \mathrm{New}$ diagnostic approaches like culture of vegetations and infected cardiac valve tissue has shown better result in blood culture negative endocarditis. ${ }^{4,5}$ The definite diagnosis of IE is made when causative microorganisms are cultured or seen histologically in vegetations and valve tissues. A positive post-surgery heart valve culture indicates an active endocardial infection and is a significant risk factor for the development of early prosthetic valve endocarditis (PVE). ${ }^{6}$ Early PVE is an infrequent complication occurring in $1-6 \%$ of patients after valve replacement surgery but is serious and possibly lethal. The objective of the study is to isolate any viable bacteria so as to guide an optimal post-operative antibiotic therapy to minimize any possibility of development of early PVE.

\section{METHODS}

A prospective observational study was conducted at Shahid Gangalal National Heart Centre (SGNHC), Bansbari, Kathmandu from November 2007 to October 2008. Ethical approval and patient consent was taken. All preoperatively diagnosed and interaoperatively suspected IE cases undergoing heart valve replacement surgery were included in the study.

Infected or possibly infected native heart valves were resected and transported in a sterile vial to the microbiology laboratory of SGNHC. They were homogenized by mincing into small pieces in a sterile petri dish using a sterile surgical scalpel. ${ }^{8}$ The cut pieces of tissue were then inoculated on Chocolate agar, $5 \%$ Sheep Blood Agar, MacConkey agar and in Brain Heart Infusion (BHI) broth. The inoculated media were incubated aerobically at $37{ }^{\circ} \mathrm{C}$, except Chocolate agar and Blood agar which were incubated in $5 \% \mathrm{CO}_{2}$. The inoculated plates were examined for bacterial growth after 24 and 48 hours of incubation. BHI broth was incubated for a week with a loopfull of broth being subcultured after every 24 hours of incubation. The bacterial isolates were identified by standard microbiological technique. The in vitro antibiotic susceptibility profile of bacterial isolates was determined by Kirby Bauer disc diffusion method. Statistical analyses were done by using Microsoft Excel 2003.

\section{RESULT}

A total of 31 heart valves resected from 27 patients were studied. Four of these patients underwent double valve replacement surgery. Of all the culture, only three were culture positive which constituted two from preoperatively diagnosed IE patients isolating Staphylococcus aureus and Enterococcus faecalis and one sample from intraoperatively suspected IE patient which grew Staphylococcus aureus (Table 1).

In antibiotic susceptibility test, all three gram positive cocci were sensitive to Vancomycin and Ciprofloxacin and resistant to Penicillin and Amoxycillin. The isolates from preoperatively diagnosed IE patients were more resistant to antibiotics tested than that from intraoperatively suspected IE patients (Table 2 ).

Total 17 (62.96\%) patients were males and 10 (37.30\%) were females with the ratio of $1.7: 1$. The mean age of the patients was $29.53( \pm 14.26)$ years. The frequency of the patients was the highest in the age group 15-35 years and the lowest in the age group $>50$ years. Among total cases, 12 were preoperatively diagnosed and 15 were intraoperatively suspected of IE (Table 3).

Among the predisposing factors for IE, rheumatic heart disease (RHD) was the most frequent one being present in $20(74.07 \%)$ cases. Congenital heart disease (CHD) were found in four (14.81\%) cases. Remaining 3 (11.11\%) cases were of without any identifiable risk factors.

Aortic valve was the most common type of resected valve comprising 17 (53.83\%) of total resected heart valves. Tricuspid valve was the least common type of heart valve comprising only 1 (3.22\%) of total samples (Table 4).

Among intraoperative surgical findings suspicious of IE, vegetation was the most common being noted in 13 $(41.93 \%)$ valve samples, followed by valve thickening in $8(25.80 \%)$ samples and valve cusp perforation in 6 (19.35\%) samples. The presence of intra-cardiac abscess was the least common finding being noted in 4 (12.90\%) samples (Table 5).

\begin{tabular}{|lll|}
\hline $\begin{array}{l}\text { Table 1. Cultural results of resected heart valve } \\
\text { samples }\end{array}$ & $\begin{array}{l}\text { Total No. of } \\
\text { heart valve } \\
\text { samples }\end{array}$ & $\begin{array}{l}\text { No. (\%) of } \\
\text { culture positive } \\
\text { samples }\end{array}$ \\
\hline $\begin{array}{l}\text { Preoperatively groups } \\
\text { diagnosed IE patients }\end{array}$ & 15 & $2(13.33)$ \\
$\begin{array}{l}\text { Intraoperatively } \\
\text { suspected IE patients }\end{array}$ & 16 & $1(6.25)$ \\
\hline
\end{tabular}

$\mathrm{IE}=$ Infective Endocarditis, No.= number 
Bacteriological Profile of Heart Valves Resected from Infective Endocarditis Patients

\begin{tabular}{|c|c|c|c|}
\hline \multirow{3}{*}{ Antibiotics } & \multicolumn{3}{|c|}{ Study groups } \\
\hline & \multicolumn{2}{|c|}{ Preoperatively diagnosed IE patients } & \multirow{2}{*}{$\begin{array}{c}\text { Intraoperatively suspected IE patients } \\
\text { Staphylococcus aureus }\end{array}$} \\
\hline & Enterococcus faecalis & Staphylococcus aureus & \\
\hline Amoxycillin & $\mathrm{R}$ & $\mathrm{R}$ & $\mathrm{R}$ \\
\hline Ceftriaxone & $\mathrm{R}$ & 1 & $S$ \\
\hline Ciprofloxacin & $S$ & $S$ & $S$ \\
\hline Cloxacillin & $\mathrm{R}$ & $\mathrm{R}$ & $S$ \\
\hline Cotrimoxazole & $\mathrm{R}$ & $S$ & $\mathrm{~S}$ \\
\hline Erythromycin & $S$ & - & - \\
\hline Gentamicin & $S$ & - & - \\
\hline Methicillin & - & $\mathrm{R}$ & $S$ \\
\hline Penicillin & $\mathrm{R}$ & $\mathrm{R}$ & $\mathrm{R}$ \\
\hline Vancomycin & $\mathrm{S}$ & $\mathrm{S}$ & $S$ \\
\hline
\end{tabular}

$\mathrm{IE}=$ Infective Endocarditis, I=Intermediate, $\mathrm{R}=$ Resistant, $\mathrm{S}=$ Sensitive, - =not included in antibiotic susceptibility test

\begin{tabular}{|c|c|c|c|c|c|}
\hline \multirow[t]{2}{*}{ Age group (years) } & \multicolumn{2}{|c|}{ Sex } & \multicolumn{2}{|c|}{ No. of patients in the study groups } & \multirow[t]{2}{*}{ Total No. (\%) } \\
\hline & Males & Females & Preoperatively diagnosed IE & Intraoperatively suspected IE & \\
\hline$<15$ & 4 & 4 & 3 & 5 & $8(29.62)$ \\
\hline $15-35$ & 7 & 4 & 5 & 6 & $11(40.74)$ \\
\hline $35-50$ & 5 & 1 & 3 & 3 & $6(22.22)$ \\
\hline$>50$ & 1 & 1 & 1 & 1 & $2(7.40)$ \\
\hline Total & 17 & 10 & 12 & 15 & $27(100)$ \\
\hline
\end{tabular}

Table 4. Types of resected heart valves

\begin{tabular}{|lcccc} 
Types of resected & \multicolumn{2}{c}{ No. of heart valves in study groups } & Total No.of resected heart \\
heart valves & Preoperatively diagnosed IE & Intraoperatively suspected IE & $\begin{array}{c}\text { valves } \\
\text { Aortic }\end{array}$ \\
Mitral & 12 & 5 & $17(54.83)$ \\
Pulmonary & 3 & 8 & $11(35.48)$ \\
Tricuspid & - & 2 & $2(6.45)$ \\
Total & - & 1 & $1(3.22)$ \\
\hline \hline
\end{tabular}

Table 5. Distribution of intra-operative surgical findings of heart valves among preoperatively diagnosed and intraoperatively suspected IE patients

\begin{tabular}{|lccc|}
\hline $\begin{array}{l}\text { Intra-operative surgical } \\
\text { findings }\end{array}$ & \multicolumn{2}{c}{ No. of heart valves in study groups } & Total No. \\
& Preoperatively diagnosed IE & Intraoperatively suspected IE & $13(41.93)$ \\
\hline Valvular vegetation & 7 & 6 & $8(25.80)$ \\
Valve thickening & 3 & 5 & $6(19.35)$ \\
Valve cusp perforation & 2 & 4 & $4(12.90)$ \\
Intra-cardiac abscess & 3 & 1 & $31(100)$ \\
Total & 15 & 16 & \\
\hline
\end{tabular}


Bacteriological Profile of Heart Valves Resected from Infective Endocarditis Patients

\section{DISCUSSION}

Culture of resected heart valves and cardiac tissue constitutes a standard post-operative microbiological diagnostic approach for guiding an optimal postoperative antibiotic therapy to minimize the possibility of early PVE.

However heart valve culture is infrequently positive ranging from $15-25 \% .^{5}$ Total of $9.67 \%$ of total resected heart valves were culture positive in this study. This finding was lower than the culture positivity of $15.08 \%$ and $24.52 \% .^{5,9}$ Such lower rate of culture positivity obtained in this study could be because of perioperative antibiotic prophylaxis, healed endocarditis, hemodilution, systemic hypothermia, cold cardioplegia and/or most importantly, broad range of preoperative antibiotic therapy. ${ }^{5}$ In addition, it could be due to inadequate cultural techniques that were insufficient to isolate fastidious bacterial and non-bacterial agents.

In this study, all preoperatively diagnosed IE patients had completed their full course of preoperative antibiotic therapy for IE. Hence, all of these patients were supposed to have healed endocarditis. It has been reported that viable microorganisms are recovered from resected cardiac valve tissue in an ever decreasing proportion as their preoperative antibiotic therapy for IE progresses. ${ }^{10}$ In this study, $13.33 \%$ of samples from preoperatively diagnosed and treated patients were culture positive growing Staphylococcus aureus and Enterococcusfaecalis. Both of these culture positive samples were evaluable with histological report corresponding to the presence of gram positive cocci and acute inflammation. Morris et al reported a lower culture positivity of $9.0 \%$ from heart valve culture among patients who had completed entire course of preoperative antibiotic therapy.

\section{CONCLUSIONS}

The microbiological investigation of resected heart valves showed higher degree of culture positivity. Therefore it is suggested to have routine microbiological investigation of all heart valves resected from diagnosed as well as intraoperatively suspected IE cases to rule out active endocarditis and to minimize the relapse of infection by guiding an optimal post-operative antibiotic therapy.

\section{ACKNOWLEDGEMENTS}

The authors are thankful to Shahid Gangalal National Heart Centre, Bansbari, Kathmandu, Nepal for providing resected heart valve samples and laboratory facility to conduct the study

\section{REFERENCES}

1. Niwa K, Nakazawa M, Tateno S, Yoshinaga M, Terai M. Infective endocarditis in congenital heart disease: Japanese national collaboration study. Heart. 2005;91:795-800.

2. Bayer AS, Bolger AF, Taugert KA, Willson W, Steckelberg J, Karchmer AW, et al. Diagnosis and management of infective endocarditis and its complications. Circulation. 1998;98:293648 .

3. Beynon RP, Bahi VK, Prendergast BD. Infective endocarditis. BMJ. 2006;333:334-9.

4. Mylonakis E, Calderwood SB. Infective endocarditis in Adults. N Eng J Med. 2001 Nov;345:1318.

5. Renzulli A, Carozza A, Marra C, Romano GP, Ismeno G, De Feo $\mathrm{M}$, et al. Are blood and valve culture predictive for long term outcome following surgery for infective endocarditis? Eur J Cardiothorac Surg. 2000;17:228-33.

6. Murashita T, Sugiki H, Kamikubo Y, Yasuda K. Surgical results for active endocarditis with prosthetic valve replacement: impact of culture- negative endocarditis on early and late outcomes. Eur J Cardiothorac Surg. 2004;26(6):1104-11.

7. Lepidi H, Casalta JP, Fournier PE, Habib G, Collart F, Roult D. Quantitative histological examination of mechanical heart valves. Clin Infect Dis. 2005 Feb;40:655-61.

8. York MK, Sharp SE, Bowler PG. Wound and soft tissue cultures. In: Isenberg HD, ed. Clinical microbiological procedures handbook. Washington DC: SM press; 2004.p .1-12.

9. Walllet F, Moukassa D, Roussel-Delvllez M, Wacrenier A, Courcol RJ. Direct microscopic examination of imprints in patients undergoing cardiac valve replacement. BMC Clin Pathol. $2001 ; 1: 6-9$.

10. Morris AJ, Drinkovic D, Pottumarthy S, Strickett MG, MacCulloch D, Lambie N, et al. Gram stain, culture and histopathological examination findings of heart valves removed because of infective endocarditis. Clin Infect Dis. 2003 Mar;36(6):697-704. 